\title{
INTEGRATION OF LEAN AND AGILE MANUFACTURING BASED ON PRINCIPLES FROM WIKINOMICS
}

\author{
DOI: 10.12776/QIP.V17I1.63
}

\author{
TATIANA USTYUGOVÁ, DARJA NOSKIEVIČOVÁ
}

\section{INTRODUCTION}

Lean and agile manufacturing are production concepts, which become more and more popular at the modern market. The success of companies depends on customers' satisfaction and the correct cost management. Nowadays we live at the period of possible, global communication. Therefore the principles from Wikinomics can be used like as integration method of lean and agile manufacturing. The topicality of this paper is focused on the creation of a steady and flexible production process and easier growth of company's success. All of these results are possible with help of involved people and global communication. The opinion, that modern companies are not ready for this collaboration, is existing. But from the theoretic side, the integration of lean and agile manufacturing with Wikinomics principles is possible. That is why the algorithm of integration of these concepts will be shown in this paper.

\section{BASICS OF LEAN AND AGILE MANUFACTURING}

Lean production was created at the Toyota Company in Japan. This production concept is focused on the elimination of waste and creation of steady and costsaving production process. The seven main types of waste were defined as (Ray, at al., 2006, pp. 4, 5):

- "unnecessary movement of employees - it is any movement of people or machines that is viewed as a value added service toward the product or service;

- waiting - this means idle time created while waiting for items that are not immediately available;

- defects - it represents the product which does not meet customer requirements; 
- unnecessary transportation movements - it is moving work over short or long distances without adding value;

- overproduction - this means making more products earlier or faster than it is required;

- inventory - it contains an inventory in excess of the minimum needs of the next transforming step;

- unnecessary process steps - it means work processes or materials that add no value to the product from the customer's viewpoint."

However the agility means an enterprise wide response to an increasingly competitive and changing business environment, based on four cardinal principles: customer satisfaction; rapid adaptation or changeover of equipment; usage of human resources and cooperation for the competition (Gunasekaran, 2001). It was defined in the research (Yusuf et al., 1999, p. 36) that "the agile manufacturing assimilates the full range of flexible production technologies, along with the lessons learned from the total quality management, "just-in-time" and lean production."

The main features (Gunasekaran, 2001, p. 32) of the agile manufacturing can be summarised as follows:

- 'Products: They are solutions to customer' individual problems. Agility is centred on the satisfaction of customer's individual needs and the quickly changeover of equipment.

- Virtual organisation: Internal and external co-operation are the strategies of choice. The aim is to bring agile products to market in minimum time by leveraging resources through co-operation.

- Entrepreneurial organisation: Companies must "organize to thrive on change”. Agile manufacturers must have personnel who can convert change to the growth.

- Knowledge-based organisation: The key differentiators in tomorrow's world will be people and information. Thus, agility contains the decentralization of authority and leverages the value of human and information resources."

In contemporary professional literature a lot of various authors tried to determine the differences between the lean and agile manufacturing. For example, authors like as (Jin-Hai et al., 2003) specify the fundamental difference that lean company may be thought of as a very productive and cost-efficient producer of goods and services. But, the agile company is primarily characterised as a very fast and efficient learning organisation. The other difference is that lean is 
focused on low-mix, high-volume production, but agile is focused on high-mix, low-volume production (Hammaduddin, 2012).

But in general, lean and agile can co-exist. Their integration can be called a leagile company (leagile - portmanteau, it is a combination of words, such as lean and agile). By opinion of author (Krishnamurthy \&Yauch, 2007), leagile company operate at different points in a manufacturing supply chain. A key element of this model is a "decoupling point". This point separates the lean processes from the agile processes. The lean processes are on the upstream side of the decoupling point, and the agile processes exist on the downstream side. The new way of the lean and agile manufacturing integration with help of Wikinomics will be shown in this paper.

\section{WIKINOMICS PRINCIPLES}

Wikinomics is the new way of modern science, which composes from two words such as Wikipedia and Economics. We can execute the integration of lean and agile manufacturing with the help of Wikinomics principles.

The main principles of this modern science are parameters of the second generation enterprise (Enterprise 2.0). These parameters are openness, peering, sharing, and acting globally. According to Wikinomics (Tapscott and Williams, 2008, pp. 21, 25, 27, 29), these principles can be explained as follows:

1) "Openness: it is associated with the words, such as transparency, freedom, flexibility. The openness means for the companies to make their boundaries porous to external ideas and human capital. It involves the transparency of pertinent information to partners, employees, customers, and others.

2) Peering: it leverages self-organization, a style of production that works more effectively than hierarchical management for certain tasks. Participants in peer production communities have many different motivations for jumping in, from altruism to achieving something that is of direct value of them.

3) Sharing: the power of this principle is not limited to the intellectual property. It is extended to other resources such as computing power, bandwidth, content, and scientific knowledge. Also, companies need to protect critical intellectual property.

4) Acting globally: global alliances, human capital, marketplaces, and peer production communities will provide access to new markets, ideas, and technologies."

By opinion of authors (Dijck and Nieborg, 2009), the companies can not rely to the collaboration with people, because only $13 \%$ of people are actual creators according to statistics and some of them wouldn't have creativity or motivation. In this paper, we do not suppose that $100 \%$ of people will take part in 
collaboration, but enterprises need to create the better conditions for actual creators, for all people who want to be involved in collaboration.

The researched algorithm of lean and agile integration will be based on the principles from Wikinomics.

\section{THE INTEGRATION ALGORITHM OF LEAN AND AGILE MANUFACTURING BASED ON PRINCIPLES FROM WIKINOMICS}

The application of Wikinomics principles has been already described in the modern articles. For example, such parameters as "Communication media to collect the customers' responses", "Efficient information systems", "Rapid evaluation and implementation of employee suggestions" are the part of the conceptual model of the agility evaluation (Vindoh and Devadasan, 2010, p. 1222). In the other agile model (Ramesh and Devadasan, 2007, pp. 185, 186), the parameters like as "Devolution of authority", "Employee involvement" or "IT integration" are described. In the source (Zhang and Sharifi, 2000, p. 509), the list of agility providers includes: "Close relationship with suppliers/customers, and involving them in planning and product development", "Using Internet and related information tools as a means of communication with outside". "Networking" is the parameter of the agile manufacturing, which includes the communication capabilities of an enterprise defined through ability to exchange information (Tsourveloudis and Valavanis, 2002, p. 338). These parameters respond to parameters of Wikinomics such as peering, openness, sharing and acting globally. The foundation of "the agile enterprise is the integration of information system/technologies, people, business process and facilities into the harmonious and flexible organization so as to respond quickly to changing circumstances" (Lin et al., 2005, p. 354). This overview of the modern enterprise model of the agile manufacturing shows that the agile production is partly including openness, peering, sharing and acting globally; the problem is in their correct application. The analysed sources of the literature don't solve the problem of the lean and agile manufacturing practical application based on the principles from Wikinomics. That is why, the basic structure of the methodology of these concepts integration with principles from Wikinomics was proposed in this paper.

As it was said before the application of these principles will lead to the agile manufacturing because the company can faster satisfy customers' individual needs with the help of employees or outsourcing and communication through IT technologies. Application of these principles will be cheaper for company, when the enterprise has the lean production already. The connection between four principles from Wikinomics, lean production and agile manufacturing is shown in Figure 1. 


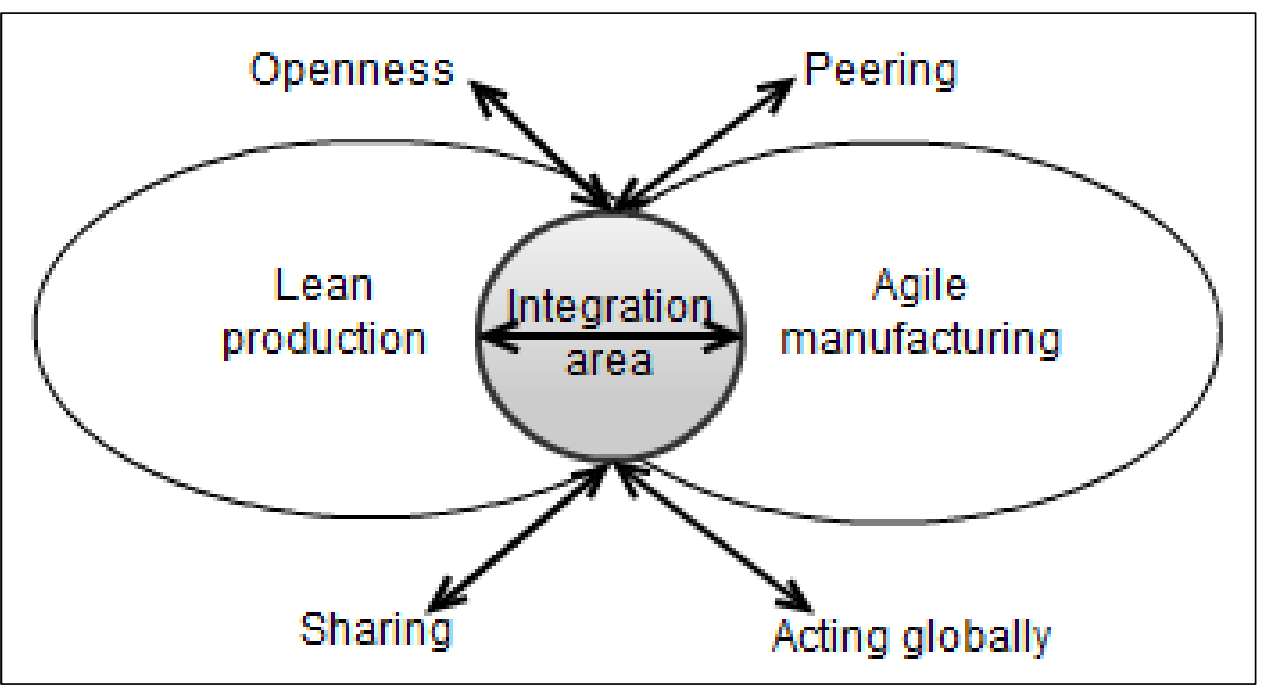

Figure 1 - The connection between principles from Wikinomics, lean and agile manufacturing (own processing)

The developed algorithm of the lean and agile manufacturing integration based on the principles from Wikinomics will include eleven stages.

First stage is the decision-making stage. The top management will need to decide, if these principles from Wikinomics will be useful for the company. The company will need to change the current situation or not. If yes, then the top management will need to define what kind of changes at the company will be made. For example, company needs to be more open, start share the information or more collaborate with personal etc.

The second stage is focused on the provision of training courses for employees. During this training, the reasons of selected changes will be explained to the employees. They will also understand how changes will be provided and what result will bring for the company. If they do not have this training, then they would not understand why they need to take part in company's transformation. Top management or specialized employees (from another company) are responsible for this stage.

The next phase is the creation of the team, which will be responsible for this project and changes at the company.

During the fourth phase, the research of the company should be conducted. This research will be executed with help of the questionnaire survey. These questions will identify if people have an interest in selected changes or not. The modification of the enterprise is impossible without interest of employees. The questionnaire will be based on the current situation at the enterprise.

Then the responsible team will analyse this questionnaire. This team will announce the report if the company is ready for these changes or not. Also, the index of the weight for each question can be added for the estimation of the company preparedness for the changes. 
The next step is an analysis of a current situation at the enterprise. This stage will include the analysis of business processes, the rate of implementation of the lean principles, organizational structure, or in what measure the principles from Wikinomics are currently used or will be used, how these principles could be integrated into the company's business system, etc. At this stage, the responsible team will make a decision what kind of information (process models, problems of company, technology of the production process etc.) will be published for the public use.

The sixth step is the creation of the system of employees' motivation. Employees are the knowledge power of the company. If they have motivation, they will take part in the company's modification and share their ideas. It is also important to create a system for the education of employees at this stage.

The next stage is the application of the lean production if the company does not have it. Lean production will lead to the elimination of wastes and to building of a steady business process. The application of the lean production is easy to start with simple methods such as " $5 \mathrm{~S}$ " or "poka-yoke" and then to apply the other methods.

The re-engineering is the eighth step. At this stage, it is important to modify the production system into the modular production for the quick changeover of equipment according to customers' requirements.

The next stage is outsourcing. The company needs to decide if some processes have to be outsourced for simplifying the production processes and for global partnership or not. It is easy to start from collaboration with locals companies. Then it is important to expand collaboration and find new partnership abroad.

The tenth step is the creation of the company web page, where information about the company, which was selected at the fifth stage, will be published. For example, the company's research problems will be published at this web page. The person, who can solve this problem, can be anybody from around the world.

The last stage is the creation an award for help and research. The reward should not be expensive, but it is important to motivate people with something. For instance (Tapscott and Williams, 2008), the P\&G company has this kind of reward, and it helps to save the budget of the company and find new solutions for their problems every year.

It is relevant to build a responsibility matrix, where the responsibility roles of the main groups of personal will be shown. Almost all processes are made with support of company employees or IT employees. The aim of this matrix is to show that the regular employees must be part of the most phases of this integration. The regular employees must join to the company changes. When the reward will be applied, or the web page will be made, then anybody (customers, investors, employees, people who do not belong to this organisation etc.) will join the company transformation, too. All of these groups of people will help to solve problems at the company. Responsibility matrix is shown in Table 1. 
Table 1 - Responsibility matrix

\begin{tabular}{ccccccc}
\hline $\begin{array}{c}\text { Number } \\
\text { of stages }\end{array}$ & $\begin{array}{c}\text { Top } \\
\text { management }\end{array}$ & $\begin{array}{c}\text { Responsible } \\
\text { team }\end{array}$ & Employees & $\begin{array}{c}\text { IT } \\
\text { staff }\end{array}$ & $\begin{array}{c}\text { Outsourcing } \\
\text { companies }\end{array}$ & $\begin{array}{c}\text { Customers } \\
\text { or others }\end{array}$ \\
\hline 1 & $\mathrm{~A}, \mathrm{R}$ & - & - & - & - & - \\
\hline 2 & $\mathrm{~A}, \mathrm{R}$ & $\mathrm{I}$ & $\mathrm{I}$ & $\mathrm{I}$ & - & - \\
\hline 3 & $\mathrm{~A}, \mathrm{R}$ & $\mathrm{I}$ & $\mathrm{I}$ & $\mathrm{I}$ & - & - \\
\hline 4 & $\mathrm{~A}$ & $\mathrm{R}$ & $\mathrm{S}$ & $\mathrm{S}$ & - & - \\
\hline 5 & $\mathrm{~A}$ & $\mathrm{R}$ & $\mathrm{S}$ & $\mathrm{S}$ & - & - \\
\hline 6 & $\mathrm{~A}$ & $\mathrm{R}$ & $\mathrm{S}$ & $\mathrm{S}$ & - & - \\
\hline 7 & $\mathrm{~A}$ & $\mathrm{R}$ & $\mathrm{S}$ & $\mathrm{S}$ & - & - \\
\hline 8 & $\mathrm{~A}$ & $\mathrm{R}$ & $\mathrm{S}$ & $\mathrm{S}$ & - & - \\
\hline 9 & $\mathrm{~A}$ & $\mathrm{R}$ & $\mathrm{I}$ & $\mathrm{S}$ & $\mathrm{S}$ & - \\
\hline 10 & $\mathrm{~A}$ & $\mathrm{~S}$ & $\mathrm{~S}$ & $\mathrm{R}$ & $\mathrm{I}$ & $\mathrm{I}$ \\
\hline 11 & $\mathrm{~A}$ & $\mathrm{R}$ & $\mathrm{I}$ & $\mathrm{S}$ & $\mathrm{I}$ & $\mathrm{I}$ \\
\hline
\end{tabular}

Legend: R-Responsible, A-Approve, I-Inform, S-Support/Assist.

The principles from Wikinomics can direct to the agile manufacturing, by their possibility to involve people to business processes of company using global communications. If company applies the lean production at the fifth stage, it will help to develop integration between two these concepts.

\section{CONCLUSION}

Integration of the lean and agile manufacturing principles should result in the creation of a steady and flexible production process, rapid customer satisfaction, increasing in openness of the company and collaboration with customers, investors, employees. This method will be developed in more detail as a part of the future research, which will be focused on the creation of the methodology for rapid adaptation of customers' requirements at the modern market. The other parts of the future research will be:

- Analysis of the possibility of the lean and agile manufacturing integration based on the principles from Wikinomics at the Czech market.

- Application of this methodology on the selected enterprise, which will help to stabilize their situation at the market.

Also, this method will help to evaluate the measure of the integration between the lean and agile manufacturing based on the fuzzy logic. 


\section{ACKNOWLEDGEMENT}

This paper was elaborated in the frame of the specific research project SP2013/49, which has been solved at the Faculty of Metallurgy and Materials Engineering, VŠB-TU Ostrava with the support of Ministry of Education, Youth and Sports, Czech Republic.

\section{REFERENCES}

Dijck, J. Van, Nieborg, D. (2009), Wikinomics and its discontents: a critical analysis of Web 2.0 business manifestos, New media \& society, Vol. 11, ISS: 4, pp. 855-874, DOI: $10.1177 / 1461444809105356$.

Gunasekaran, A. (2001), Agile manufacturing: $21^{\text {st }}$ century competitive strategy, Elsevier, UK, p. 820.

Hammaduddin, (2012), Agile manufacturing is an operational strategy focused on inducing velocity and flexibility in a make, Slide Share [blog], April 29, Available at: <http://www.slideshare.net/Hammaduddin/agile-manufacturing-isan-operational-strategy-focused-on-inducing-velocity-and-flexibility-in-a-make $>$ [Accessed 24 April 2013]

Jin-Hai, L., Anderson, A. and Harrison, R. (2003), The evolution of agile manufacturing, Business process Management Journal, Vol. 9, Iss: 2, pp. 170189, DOI: $10.1108 / 14637150310468380$.

Krishnamurthy, R., Yauch, C. (2007), Leagile manufacturing: a proposed corporate infrastructure, International Journal of Operations \& Production Management, Vol. 27 Iss: 6, pp. 588-604, DOI: 10.1108/01443570710750277.

Lin, C., Chiu, H., Tseng, Y. (2005), Agility evaluation using fuzzy logic, International Journal of Production Economics, Vol. 101, Iss: 2, pp. 353-368, DOI: 10.1016/j.ijpe.2005.01.011.

Ramesh, G., Devadasan, S. (2007), Literature review on the agile manufacturing criteria, Journal of Manufacturing Technology Management, Vol. 18, pp. 182201, DOI: 10.1108/17410380710722890.

Ray, B., Ripley, P., Neal, D. (2006), Lean Manufacturing - A Systematic Approach to Improving Productivity in the Precast Concrete Industry, PCI Journal, pp. 2-11.

Tapscott D., Williams, D. (2008), Wikinomics, Atlantic Books, London, p. 351.

Tsourveloudis, N., Valavanis, K. (2002), On the Measurement of Enterprise Agility, Journal of Intelligent and Robotic Systems, Vol. 33, Iss: 3, pp. 329-342, DOI: 10.1023/A:1015096909316.

Vinodh, S., Devadasan, S. (2010), Twenty criteria based agility assessment using fuzzy logic approach, The International Journal of Advanced Manufacturing Technology, Vol. 54, Iss: 9-12, pp. 1219-1231, DOI: 10.1007/s00170-010-30156. 
Yusuf, Y., Sarhadi, M., Gunasekaran, A. (1999), Agile manufacturing: drivers, concepts and attributes, International Journal of Production Economics, Vol. 62, Iss: 1-2, pp. 33-43, DOI: 10.1016/S0925-5273(98)00219-9.

Zhang, Y., Sharifi, H. (2000), A methodology for achieving agility in manufacturing organisations, International Journal of Operations \& Production Management, Vol. 20, pp. 496-512, DOI: 10.1108/01443570010314818.

\section{ABOUT THE AUTHORS}

Ing. Tatiana Ustyugová, VŠB - Technical University of Ostrava, Faculty of Metallurgy and Materials Engineering, Department of Quality Management, 17. listopadu, Ostrava-Poruba 708 33, Czech Republic, e-mail: tatiana.ustyugova.st@vsb.cz.

Prof. Ing. Darja Noskievičová, CSc., VŠB - Technical University of Ostrava, Faculty of Metallurgy and Materials Engineering, Department of Quality Management, 17. listopadu, Ostrava-Poruba 708 33, Czech Republic, e-mail: darja.noskievicova@vsb.cz. 